\title{
Effects of sheep grazing and temporal variability on population dynamics of the clonal herb Geranium sylvaticum in an alpine habitat
}

\author{
Marianne Evju • Rune Halvorsen • \\ Knut Rydgren • Gunnar Austrheim • \\ Atle Mysterud
}

Received: 1 October 2010/ Accepted: 14 February 2011/Published online: 26 February 2011

(C) The Author(s) 2011. This article is published with open access at Springerlink.com

\begin{abstract}
An improved understanding of population-level consequences of grazing on plants can be facilitated by an assessment of grazing effects on all stages in the life-cycle. In this study, 6 years of demographic data for three populations of the perennial herb Geranium sylvaticum were analysed. We examined the effects of sheep grazing (high sheep
\end{abstract}

Electronic supplementary material The online version of this article (doi:10.1007/s11258-011-9906-2) contains supplementary material, which is available to authorized users.

M. Evju · R. Halvorsen

Department of Research and Collections, Natural History Museum, University of Oslo, P.O. Box 1172 Blindern, 0318 Oslo, Norway

\section{Evju ( $ه)$}

Norwegian Institute for Nature Research (NINA), Gaustadalléen 21, 0349 Oslo, Norway

e-mail: marianne.evju@nina.no

K. Rydgren

Faculty of Science, Sogn og Fjordane University College, P.O. Box 133, 6851 Sogndal, Norway

\section{G. Austrheim}

Museum of Natural History and Archaeology, Norwegian University of Science and Technology, 7491 Trondheim, Norway

\section{A. Mysterud}

Centre for Evolutionary and Ecological Synthesis (CEES), Department of Biology, University of Oslo, P.O. Box 1066 Blindern, 0316 Oslo, Norway density, low sheep density and no sheep) and interannual climatic variability on vital rates and population growth rates $(\lambda)$. Grazing did not affect survival or flowering rates, but reduced rates of growth and increased rates of clonal reproduction. At the population level, high contributions from retrogression and clonal reproduction buffered reduced rates of growth and stasis, and no consistent differences in $\lambda$ between populations exposed to different sheep densities were found. Instead, large betweenyear variability in $\lambda$, independent of sheep density, was detected, related to variation in the local summer climate. The results indicated, however, that grazing effects on $\lambda$ were more severe in unfavourable than in normal years. Our study highlights that increased clonal reproduction rates functioned as a tolerance mechanism towards grazing in this herb, which forms a mechanism to explain how moderate population responses to grazing in some herbs can arise.

Keywords Herbivory - Interannual variability · LTRE analysis · Matrix projection models . Plant tolerance

\section{Introduction}

Vertebrate grazers act directly and indirectly upon individual plants by removing biomass, altering resource availability, changing the physical environment and modifying intra- and interspecific interactions 
(Mulder 1999). For a given plant species, however, stages in its life-cycle may be affected by grazers in different ways. Vertebrate grazers seem, e.g., to prefer large ramets over small (Ehrlén 1995a), and grazing can reduce survival (Ehrlén 1995a), growth (Lennartsson and Oostermeijer 2001) and seed production (Bastrenta 1991; Knight 2004) of individual plants. At the same time, the grazers can facilitate seedling recruitment (Lennartsson and Oostermeijer 2001) and increased survival of juvenile plants (Brys et al. 2004; Ehrlén et al. 2005) through prevention of litter accumulation and creation of vegetation gaps. In order to evaluate population-level consequences of grazing, grazing effects need to be assessed for all stages in the lifecycle.

Disturbance, such as trampling and grazing, can increase rates of clonal reproduction in vascular plants (Diemer and Schmid 2001; Lamoureaux et al. 2003) and bryophytes (Rydgren et al. 2001). The plants' capacity for clonal reproduction has been predicted to buffer plant populations from negative effects of herbivores (Maron and Crone 2006), and Tolvanen et al. (2001) found higher rates of clonal reproduction in grazed than in ungrazed sedge populations. However, to our knowledge, no studies exist of vertebrate grazing effects on the population dynamics of clonal herbs (see also review by Maron and Crone (2006)).

The magnitude of population-level effects of grazing will depend not only on how grazing as such affects vital rates of the plant, but also on grazing pressure (Hunt 2001; Rydgren et al. 2007), and Knight (2003) found a negative correlation between the proportion of plants being grazed and the population growth rate $(\lambda)$ of Trillium grandiflorum. Grazing pressure, i.e., the proportion of plants in the population being grazed, depends on herbivore density, but also on the abundance and quality of available forage plants (Augustine and McNaughton 1998; Kausrud et al. 2006). In alpine areas, a short growing season makes vegetation development strongly dependent on weather conditions (Lenart et al. 2002), and consequently, grazing pressure can vary among years, even at constant herbivore densities (Evju et al. 2006; Jefferies 1999). Furthermore, the plants' ability to compensate for lost biomass (plant tolerance) depends on environmental factors such as light, nutrient and water supply (Cronin and Lodge 2003; Maschinski and Whitham 1989). Plant tolerance may thus vary both in space and time (Lennartsson et al. 1998), and interannual variability in local climate may interact with grazing to affect plant population dynamics (Evju et al. 2010), e.g. through a larger reduction in population growth rate in unfavorable years in grazed versus ungrazed populations (Bastrenta et al. 1995; Martorell 2007).

In this study, we used 6 years of demographic data for a perennial, clonal herb, Geranium sylvaticum. The species is reported to be eaten regularly, but at low intensity (i.e. that only a small proportion of each plant was grazed) by sheep (Hæggström 1990), and is found to benefit from exclusion of vertebrate herbivores in low-productive alpine habitats (Moen and Oksanen 1998; Olofsson 2001). Three populations, located in areas with high sheep density (80 sheep $\mathrm{km}^{-2}$ ), low sheep density (25 sheep $\mathrm{km}^{-2}$ ) and no sheep within a landscape-scale sheep grazing experiment, were monitored from 2002 through 2007. Using a combination of stage-based matrix projection models and linear mixed-effect models, we test the following predictions in this study: (1) grazing reduces rates of growth, survival and flowering of Geranium sylvaticum whereas rates of clonal reproduction are increased by grazing, (2) these effects of grazing on vital rates translate to the population level as a lowered population growth rate $(\lambda)$ at high sheep density, whereas cessation of grazing affects $\lambda$ positively, (3) effects of grazing vary between years dependent on interannual climatic variability.

\section{Materials and methods}

\section{Study species}

Geranium sylvaticum L. (Geraniaceae) is a tall $(20-80 \mathrm{~cm})$ and long-lived, iteroparous rhizomatous herb with wide ecological amplitude, including a broad range of different forest and meadow types, from the nemoral to the low alpine zone (Lid and Lid 2005). G. sylvaticum has a short, unbranched rhizome $(3-10 \mathrm{~cm})$, a rosette of basal leaves with long petioles, and produces one to several flowering shoots per ramet. Meristems on the rhizome can be activated, giving rise to clonal offspring (Salomonson et al. 1994; Klimeš and Klimešová 1999). The species may flower at the age of 7-10 years (Salomonson et al. 1994). Fruits contain up to five seeds, which 
mature ca. 3 weeks after flowering ( ̊gren and Willson 1994). Seeds are dispersed through explosive dehiscence. The species has a transient seed bank; seeds survive in the soil for less than 1 year (Thompson et al. 1997; Molau and Larsson 2000).

Experimental design and sampling procedure

The study was carried out within a landscape-scale experiment located on a south-facing hillside in the low alpine zone (1050-1300 m a.s.l) in Hol municipality, Buskerud county, southern Norway (between 60 $40^{\prime}-$ $60^{\circ} 45^{\prime} \mathrm{N}$ and $\left.7^{\circ} 55^{\prime}-8^{\circ} 00^{\prime} \mathrm{E}\right)$. The bedrock consists of meta-arkose (Sigmond 1998), and the soil is moderately base-rich. The vegetation consists of a mosaic of low shrubs and grass-dominated meadow (Austrheim et al. 2005). In 2001, $17.3 \mathrm{~km}$ of standard sheep fences was set up, constituting an enclosure covering $2.7 \mathrm{~km}^{2}$ (Fig. 1). Three treatments, high sheep density ( 80 sheep $\mathrm{km}^{-2}$ ), low sheep density ( 25 sheep $\mathrm{km}^{-2}$ ), and no sheep, were replicated thrice. Thus, nine fenced parallel sub-enclosures each covering ca. $0.3 \mathrm{~km}^{2}$ and running from low to high altitude were distributed within the experimental area. Sheep densities were set to be representative of normal sheep densities in alpine habitats of Norway (Evju 2009).The first experimental grazing season was 2002. Grazing lasted from the last week of June to the last week of August/first week of September all years.
The mean annual precipitation (normal period 1961-90; Førland 1993) is estimated to be about $1000 \mathrm{~mm}$ (Evju 2009). Mean annual temperature is $-1.5^{\circ} \mathrm{C}$, with January temperature $-10.8^{\circ} \mathrm{C}$ and July temperature $8.9^{\circ} \mathrm{C}$. During the study period, the summers of 2003 and 2006 were particularly warm (Table 1), and the summers of 2004 and 2006 were particularly dry, with $70-75 \%$ of normal precipitation during July.

Twenty permanent plots for vegetation monitoring $\left(0.5 \times 0.5 \mathrm{~m}^{2}\right.$ each $)$ were distributed in each subenclosure at the start of the experiment in 2001 following a random stratified design (see Austrheim et al. (2008) for details; Fig. 1). These plots form the basis for the present study, in which Geranium sylvaticum ramets were monitored at annual censuses (late July/early August) from 2002 through 2007. One additional census was performed in late June each year except 2006 to detect newly emerged seedlings.

In 2002, 200 ramets (aboveground parts) were collected outside the permanent plots, measured, dried to constant weight at $80^{\circ} \mathrm{C}$ and weighed. We constructed a multiple regression model of dry mass (DM, in $\mathrm{mg}$ ) as a function of five morphological variables; plant height, number of leaves, length, and width of the largest leaf and stem diameter at the base, with $R_{\text {adj }}^{2}=0.944$ (see Online Resource 1 for details). All ramets located within the 180 permanent plots were non-destructively tagged in 2002 . At each census, the
Fig. 1 The experimental design, with sub-enclosures nested in blocks, and with three replicates of the treatments no sheep (control), low sheep density and high sheep density. Twenty permanent plots $\left(0.5 \times 0.5 \mathrm{~m}^{2}\right.$; green dots $)$ in which $G$. sylvaticum was monitored, are located within each sub-enclosure

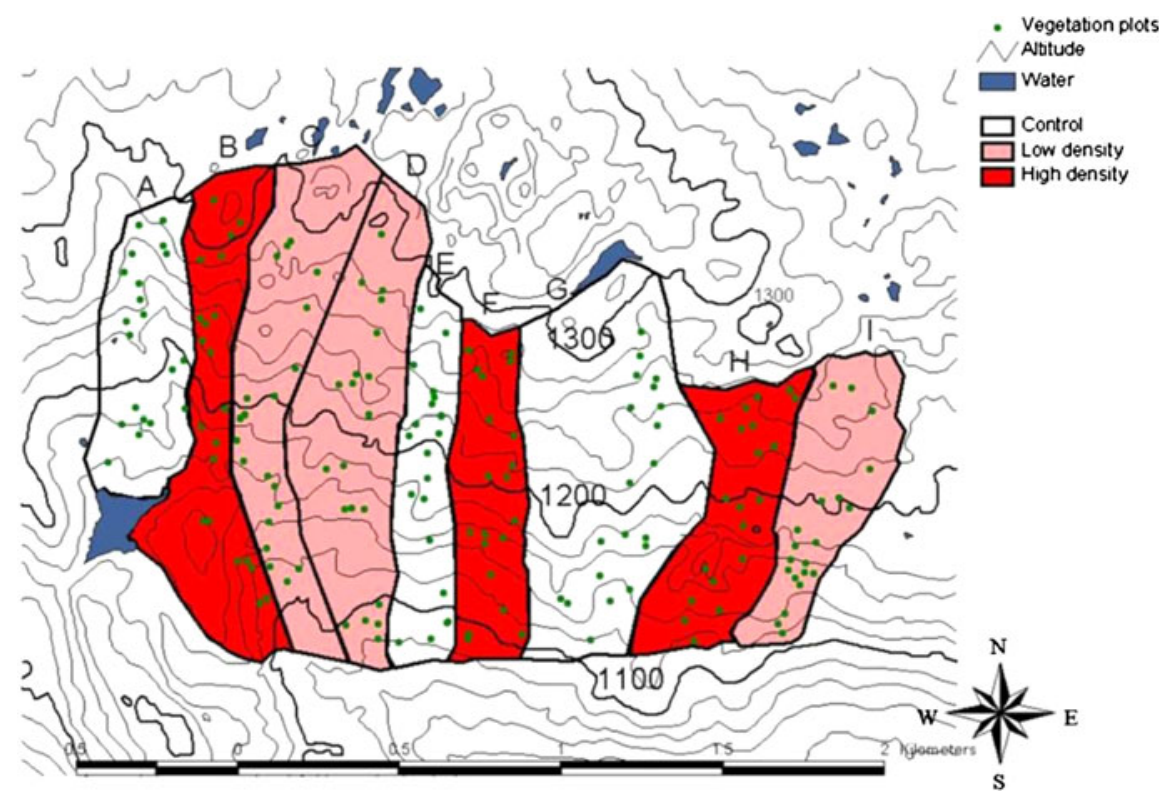


Table 1 Mean July temperature and total July precipitation each year during the study period. Temperature and precipitation data (including the average temperature and precipitation

\begin{tabular}{llllllll}
\hline & 2002 & 2003 & 2004 & 2005 & 2006 & 2007 & $1961-1990$ \\
\hline July temp $\left({ }^{\circ} \mathrm{C}\right)$ & 10.2 & 11.9 & 8.7 & 10.7 & 11.8 & 8.5 & 8.9 \\
July precipitation $(\mathrm{mm})$ & 156 & 119 & 73 & 168 & 80 & 307 & 105 \\
Snow cover $(\%)$ & 1.0 & 1.0 & 0.6 & 7.2 & 0.1 & 4.8 & - \\
\hline
\end{tabular}

These data are derived through interpolation from surrounding weather stations and provided for three $1 \times 1 \mathrm{~km}^{2}$ grid cells covering the study area. Presented data are the mean for these grid cells. Snow cover is estimated as the percentage of the study area covered by snow on July 1 each year

five morphological variables were recorded on each ramet, and we subsequently used the regression model to estimate plant size (DM). In addition, at each census, grazing marks on ramets were recorded and the number of capsules was counted on reproductive ramets.

In plots with high densities of G. sylvaticum ramets, a pre-defined subset of the plot which included a minimum of 20 ramets was used. This subset was kept constant for the rest of the study. New plants that appeared in the plots were also tagged and measured, and their origin judged (from seeds, clonal offspring or by immigration). Seedlings were defined as all small plants (for classification of life-stages, see below) that were $<1$ year old. Mother ramet and clonal offspring relations could not be established non-destructively. Based on excavations of underground structures outside the plots, we assigned new, non-seedling plants to the nearest plant if one was found within a $6 \mathrm{~cm}$ distance. New, non-seedling plants appearing close to the plot borders were defined as immigrants.

Table 2 Definitions of life-stage classes and important demographic characteristics of these classes; average mortality (\% of plants in that stage class at time $t$ recorded as dead at $t+1)$, fecundity ( $\%$ of plants in that stage class setting seeds), clonal for the period 1961-90) are provided for the study area by The Norwegian Meteorological Institute
Six permanent plots were excluded as their corners (and, hence, ramets) could not be exactly re-located (four in high and two in low sheep density).

\section{Life-stage classification and matrix parameterisation}

We used the estimated plant size $\left(\log _{2} \mathrm{DM}\right)$ combined with reproductive criteria to define life-stage classes. Through generalised linear mixed-effect models (using plant ID as a random factor), we found a positive dependence of survival on size $(G=64.3$, $P<0.0001, n=2567$; Table 2); positive dependence of the probability of flowering on size $(G=257.2$, $P<0.0001, n=2567)$ and a weaker positive dependence of the probability of clonal reproduction on size $(G=78.9, \quad P<0.0001, n=2567)$. There was a reproduction threshold at $\log _{2} \mathrm{DM}=5$ and a marked increase in the probability of sexual reproduction above $\log _{2} \mathrm{DM}=7$ (Table 2 ). We thus pragmatically defined life-stage classes so that approximately the

\begin{tabular}{|c|c|c|c|c|c|}
\hline Stage class & Definition & Mortality (\%) & Fecundity (\%) & $\begin{array}{l}\text { Clonal } \\
\text { reproduction }(\%)\end{array}$ & $\begin{array}{l}\text { Conditional lifespan } \\
\text { (mean } \pm \mathrm{SD})\end{array}$ \\
\hline Seedling & $<1$-year-old & 39.3 & 0.0 & 0.0 & $5.4 \pm 7.0$ \\
\hline Clonal offspring & $\begin{array}{l}\text { Produced through clonal } \\
\text { reproduction }\end{array}$ & 17.3 & 0.7 & 2.9 & $8.6 \pm 8.6$ \\
\hline Small & $\log _{2} \mathrm{DM}<3$ & 18.9 & 0.0 & 1.8 & $7.0 \pm 7.6$ \\
\hline Medium & $3 \leq \log _{2} \mathrm{DM}<5$ & 12.8 & 0.0 & 4.4 & $8.7 \pm 8.4$ \\
\hline Large & $5 \leq \log _{2} \mathrm{DM}<7$ & 7.2 & 0.3 & 8.1 & $10.1 \pm 8.8$ \\
\hline X-large & $\log _{2} \mathrm{DM} \geq 7$ & 6.4 & 12.9 & 13.6 & $10.7 \pm 9.0$ \\
\hline Dormant & Not observed & Not observed & 0.0 & 0.0 & $9.7 \pm 8.4$ \\
\hline
\end{tabular}

reproduction (\% of plants in that stage class producing clonal offspring), and conditional lifespan (average time to death for individuals that enter that life-stage class), pooled over populations and years 
same number of plants was present in each class, and at the same time each class represented a fourfold increase of size compared to the smaller class.

There were not enough ramets present in all subenclosures to construct transition matrices for each year and sub-enclosure separately. We therefore pooled data for all sub-enclosures exposed to the same sheep density and treated the data as one population.

To estimate seed production, 100 reproducing ramets were collected in 2007 (evenly distributed among the nine sub-enclosures). The number of capsules and seeds were counted on each ramet in the laboratory. The number of intact seeds per capsule was not related to individual ramet size or to the number of capsules per individual, and did not vary significantly among the sheep density treatments (M. Evju, unpublished data). The data were therefore pooled to give a species-specific mean of 2.35 seeds per capsule, which was treated as constant over all years. To our knowledge, there are no studies of variation in seed set with local climate in $G$. sylvaticum, although the species has been found to have a higher seed number per capsule in high- than in lowlight habitats (Korhonen et al. 2004). Thus, the between-year variation in seed production could be underestimated in our study.

Fecundity was expressed as the average number of seedlings (number of seeds $\times$ estimated seedling emergence rate) produced by a ramet in a given stage class. We calculated seedling emergence rates separately for each population and year as the number of seedlings in $t+1$ divided by the number of seeds produced in $t$ (recorded number of capsules $\times 2.35$ seeds per capsule). Seeds germinated throughout the season (M. Evju, personal observation), and new plants at the late June census had sometimes passed the cotyledon stage. We therefore defined all small plants $<1$-year-old as seedlings. In the first year, noncotyledon seedlings could not be distinguished from small plants, and we therefore used the populationspecific mean of observations from 2003-2007 as estimates for transition probabilities from seedlings to all other stages for 2002-2003. Similarly, origin by clonal branching could not be decided in 2002, and we therefore used the population-specific mean of observations for 2003-2007 as estimates for transition probabilities from clonal offspring in 2002-2003.

Prolonged dormancy, i.e., failure to produce above-ground parts for one or several growing seasons (Lesica and Steele 1994) was observed in 102 of the 3117 transitions from stage to fate recorded in the study. Of these, only five plants went dormant for two consecutive growing seasons. Mortality rates for dormant ramets cannot be observed directly, but can be estimated (Kéry et al. 2005). We estimated mortality rates based on the assumption that ramets entering dormancy had the same mortality rates as non-dormant ramets, and thus calculated a weighted mean mortality as the life-stage specific mortality rate $x$ the proportion of dormant plants from this life-stage class, summed over all life-stage classes. For transitions from the dormant stage at time $t$ to all other stages at $t+1$, we assumed that all transition rates were affected equally by mortality in the dormant stage and reduced them by subtracting from observed transition rates the estimated mortality rate (Evju et al. 2010). As transitions to dormancy could not be observed in the last transition period (2006-2007), pooled data from 2002-2006 were used to estimate transition rates from each life-stage class to dormancy for each population.

To summarise the demographic processes, we classified each transition in the life-cycle as belonging to one of five life-history components (Fig. 2; cf. Silvertown et al. 1993): fecundity ( $F$ recruitment of seedlings from the seed production); clonal reproduction ( $C$ recruitment of clonal offspring); growth ( $G$ transitions to a larger life-stage class); stasis ( $S$ survival in the same life-stage class, including survival of clonal offspring) and retrogression ( $R$ transitions to a smaller life-stage class or to dormancy).

In addition to pooling data for estimating seedling and clonal offspring transitions for 2002-2003 (see above), we used population-specific data pooled over years to estimate transition probabilities for stage classes containing less than seven ramets at time $t$ (Online Resource 2). This was done for transitions from dormancy in one transition period in the high sheep density population, and in three transition periods in the low sheep density and no sheep populations. In addition, in the no sheep population the low number of clonal offspring prevented calculation of year-specific transition probabilities from this life-stage class (see Online Resource 2).

For each life-stage class the conditional total lifespan, i.e., average time to death for individuals that survive to that the given stage, was calculated (Ehrlén and Lehtilä 2002; Table 2). 
Fig. 2 The life-cycle graph and transition matrix of Geranium sylvaticum. Matrix elements are subdivided into: fecundity

$(F$ mean number of seedlings produced per plant per stage), clonal reproduction $(C$ mean number of clonal offspring produced per plant per stage), growth ( $G$ transitions to a larger life-stage class), stasis ( $S$ survival in the same lifestage class, including survival of clonal offspring), and retrogression $(R$ transitions to a smaller life-stage class or to dormancy). In the graph, only transitions with elasticity $>0.01$ are shown as arrows (based on the pooled matrix of the full dataset)

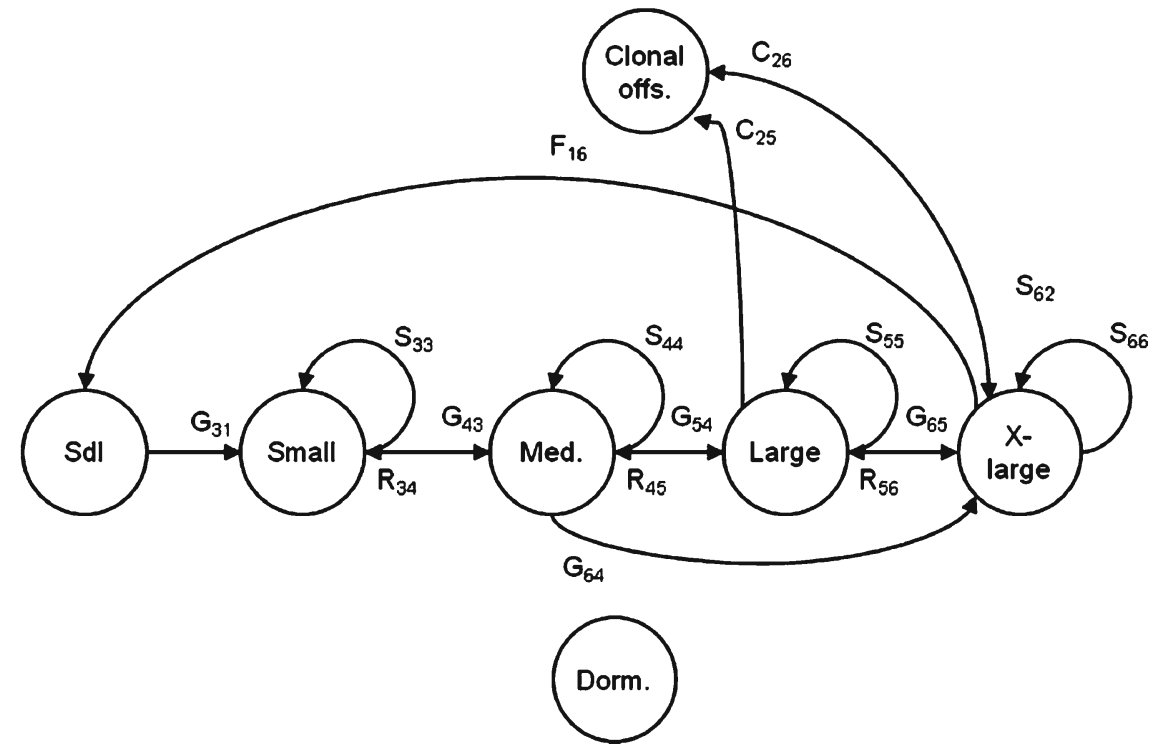

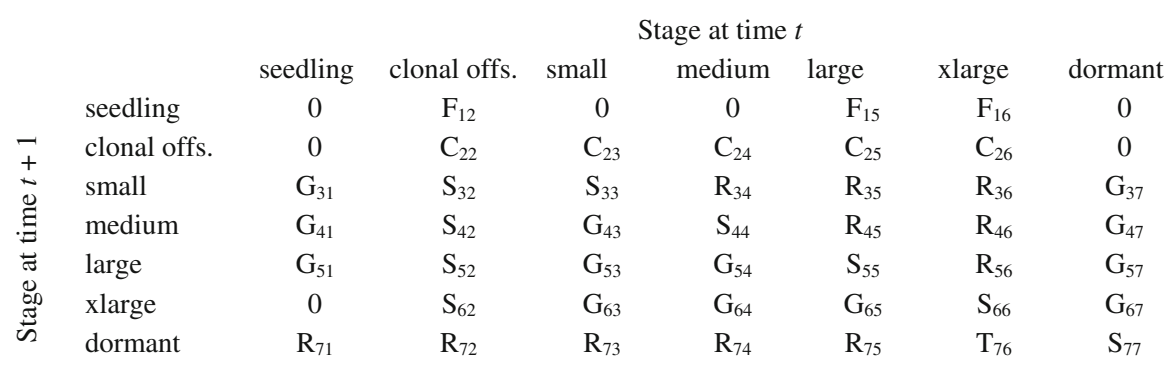

Statistical analyses and transition matrix modelling

We used generalised linear mixed-effect models (GLMM; Pinheiro and Bates 2000) to analyse the effects of sheep density, sheep grazing and local climate on survival, growth, flowering (probability of flowering and number of fruits produced) and clonal reproduction. As all vital rates were strongly size dependent (Table 2), we included plant size $\left(\log _{2} \mathrm{DM}\right)$ as a covariate in the analyses. Plant ID, plot and sub-enclosure were included as random factors in the models to account for repeated measurements on individual plants as well as the spatial dependency of plants within plots and plots within sub-enclosures. To describe local weather conditions, we used mean July temperature and total July precipitation as proxies for overall favourableness of growth during the growing season, representing mid-summer conditions during a short alpine growing season (cf., Callaghan et al. 1989). We tested for possible interactions between local climate and sheep density. Models were evaluated using AIC. The effect of sheep grazing on plant growth was analysed comparing size in $t-1$ and $t+1$ for plants that were grazed and ungrazed in $t$. In this analysis, we only included plants for which no grazing was recorded in $t-1$ and $t+1$, and for which we had reliable size estimates in all 3 years.

We constructed 15 stage-based transition matrices with one-year projection intervals (three populations $\times$ five transition periods; Online Resource 2). For each matrix, the population growth rate $\lambda$ (maximum eigenvalue of the projection matrix) and elasticities (de Kroon et al. 2000; Caswell 2001) were calculated. Elasticity values were summed for each life-history component. We calculated Pearson's correlation coefficient between the summed elasticities and $\lambda$. We used one-way ANOVA to analyse the difference in $\lambda$ between years and between sheep density treatments, and to investigate differences in summed elasticities of life-history components between treatments. ANOVA was followed by Tukey's test and adjusted p-values were used (Crawley 2007). 
We used bootstrapping to construct confidence intervals around $\lambda$. For each combination of treatment and transition period, the plants were resampled with replacement to construct bootstrap samples. The size of the bootstrap sample was set equal to the size of the original data set. Three thousand bootstrap samples were constructed for each transition matrix. The percentile method (Caswell 2001) was used to construct $95 \%$ confidence intervals around the median $\lambda$. For transition probabilities from seedlings and clonal offspring in the first year (non-observable), we used pooled values from 2003-2007 for each population.

We used life-table response experiments (LTRE) to quantify the contribution of different matrix elements to the differences in $\lambda$ between populations and years (Caswell 2001). We used sheep density treatment and year as fixed effects and constructed a two-way LTRE model for population growth in treatment $m$ and year $n$, following Caswell (2001):

$\lambda^{(m n)}=\lambda^{(\cdot)}+\alpha_{m}+\beta_{n}+(\alpha \beta)_{m n}$

where $\lambda^{(\cdot)}$ is the growth rate calculated from $\mathbf{A}^{(\cdot)}$, the grand mean of all the matrices, and $\alpha_{\mathrm{m}}, \beta_{\mathrm{n}}$ and $(\alpha \beta)_{\mathrm{mn}}$ are the treatment, year and interaction effects, respectively. To investigate if some life-history components contributed consistently to LTRE year effects, we calculated Pearson's correlation coefficient between LTRE year effect and summed contribution from each life-history component.

All statistical analyses were carried out using $\mathrm{R}$ 2.10.1 (R Development Core Team 2009). Analyses involving matrix computations were performed with the $\mathrm{R}$ package popbio (Stubben et al. 2008), and mixed-effect models were run with the $\mathrm{R}$ packages nlme and lme4 (Bates and Maechler 2010; Pinheiro et al. 2008).

\section{Results}

Effects of local weather and grazing on vital rates

The proportion of grazed ramets varied among treatments and years; between $7-16 \%$ and $2-5 \%$ of ramets in the populations exposed to high and low sheep densities were grazed, respectively (Fig. 3). There was no significant difference between years in

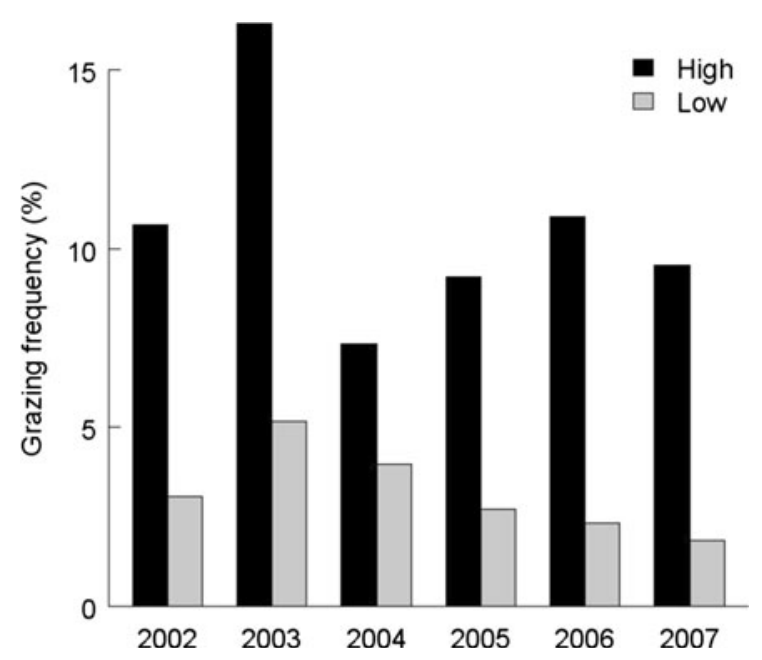

Fig. 3 Grazing frequency, measured as the proportion of plants (excluding seedlings and dormant plants) grazed by sheep in the high and low sheep density treatments from 2002 to 2007

the probability of being grazed $(G=8.04$, df $=5$, $P=0.154, n=2431$ ), but the probability of being grazed was significantly higher in the high than in the low sheep density population $(G=18.78$, $\mathrm{df}=2$, $P<0.0001, n=2431)$.

Grazed ramets had higher probability of clonal reproduction (odds ratio $\mathrm{OR}=2.4,95 \% \mathrm{CI}=$ 1.2-4.7; Fig 4a), but at the same time grazing affected growth negatively; ramets that were grazed in $t$ grew less from $t-1$ to $t+1$ than ungrazed ramets, and this effect was largest for large ramets (Fig. 4b; Online Resource 3). However, grazing in $t-1$ did not affect survival, flowering rates or fruit production in $t$ (Online Resource 3).

Survival from $t$ to $t+1$ was positively related to mean July temperature in $t+1$ (Table 3 ). Survival was not reduced by grazing and did not vary between sheep density treatments. Plant growth (ramet size in $t$ as a function of size in $t-1$ ) was positively related with mean July temperature and precipitation, but grazing reduced ramet size significantly (Table 3). A significant grazing $\times$ precipitation interaction revealed that during wet summers, the size differences between grazed and ungrazed ramets were smaller. The probability of flowering in $t$ was positively related to mean July temperatures in both $t-1$ and $t$ (Table 3). 

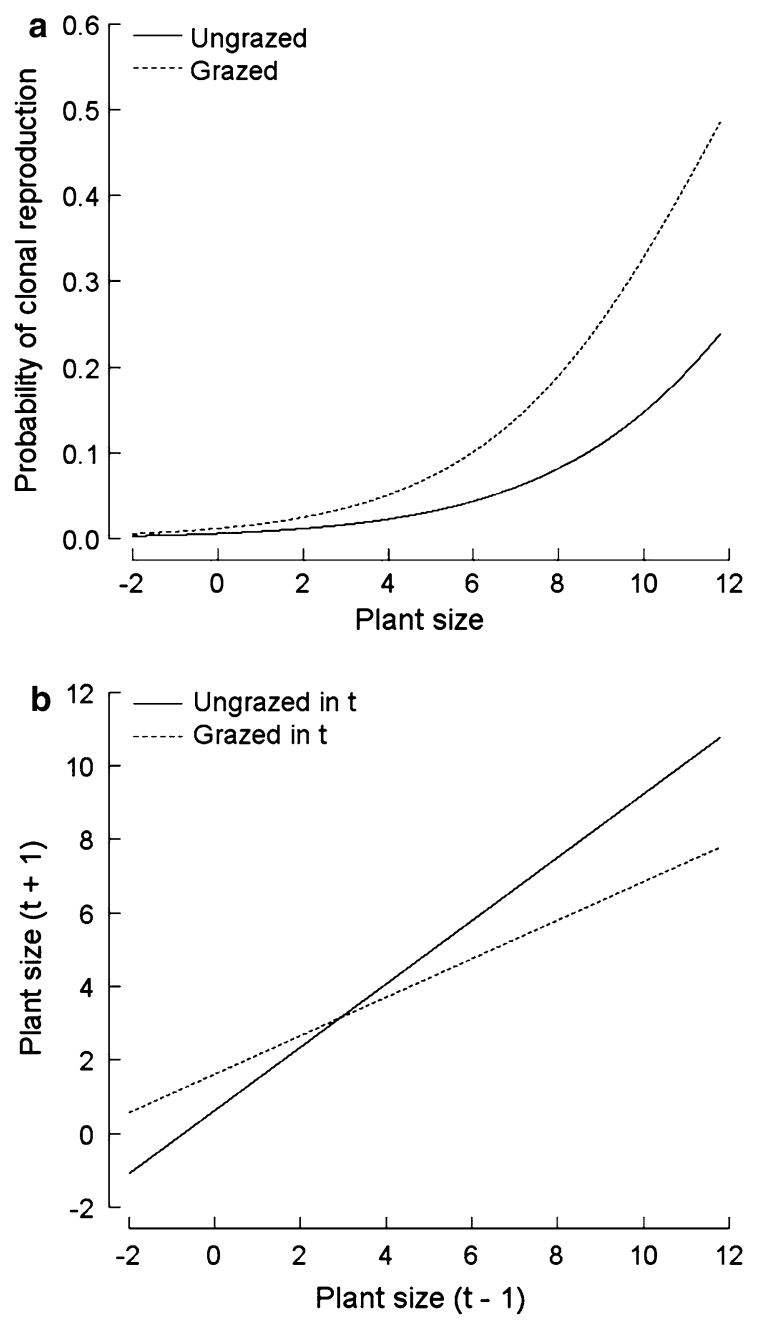

Fig. 4 a The probability of producing clonal offspring as a function of plant size (in $\log _{2}$ DM-units) for grazed $(n=144)$, and ungrazed $(n=2423)$ plants, and b plant size (in $\log _{2} \mathrm{DM}$ units) in $t+1$ as a function of size in $t-1$ for plants that were grazed $(n=65)$ and ungrazed $(n=1309)$ in $t$

Population growth rates and elasticities

The projected population growth rate $(\lambda)$ varied between 0.827 (high density 2005-2006) and 1.179 (low density 2004-2005; Fig. 5). There was no significant difference in $\lambda$ between sheep density treatments $\left(\mathrm{F}_{2,12}=0.269, P=0.768\right)$, but a significant difference between years $\left(F_{4,10}=8.506\right.$, $P=0.003$ ) was found.

There was a positive correlation between $\lambda$ and summed elasticities for fecundity and growth, and a negative correlation between $\lambda$ and retrogression (Fig. 6). This showed that actively growing populations
Table 3 Generalised linear mixed-effect models (GLMM) of survival (response binomial, no. of observations $=2670$, no. of plant identities (IDs) $=901$ ), plant size (response continuous, no. of obs. $=1374$, no. of IDs $=591$ ) and flowering probability (response binomial, no. of obs. $=2507$, no. of IDs $=800$ ) as a function of summer temperature, precipitation and grazing. Parameter estimates for random factors (plant ID, plot and enclosure) are not shown

\begin{tabular}{lrlrr}
\hline Fixed effects & Estimate & SE & \multicolumn{2}{l}{$P$} \\
\hline Survival & & & & \\
$\quad$ Intercept & 0.270 & 0.425 & 0.636 & 0.525 \\
Plant size & 0.238 & 0.026 & 9.120 & $<0.001$ \\
July temperature & 0.082 & 0.041 & 2.030 & 0.042 \\
Plant size $(t)$ & & & & \\
Intercept & 0.055 & 0.303 & 0.182 & 0.855 \\
Plant size $(t-1)$ & 0.808 & 0.012 & 64.921 & $<0.001$ \\
Grazing & -1.544 & 0.260 & -5.942 & $<0.001$ \\
July temperature & 0.053 & 0.024 & 2.252 & 0.025 \\
July precipitation & 0.0014 & 0.0004 & 3.536 & $<0.001$ \\
Grazing $\times$ July & 0.0064 & 0.0014 & 4.516 & $<0.001$ \\
precipitation & & & & \\
Flowering & & & & \\
Intercept & -27.216 & 3.655 & -7.447 & $<0.001$ \\
Plant size & 1.763 & 0.190 & 9.296 & $<0.001$ \\
July temperature & 0.621 & 0.188 & 3.307 & $<0.001$ \\
( $t-1)$ & & & & \\
July temperature $(t)$ & 0.369 & 0.129 & 2.871 & 0.004 \\
\hline & & & &
\end{tabular}

were characterised by high elasticities for fecundity and growth. Summed elasticities for clonal reproduction (C) varied among treatments $\left(F_{2,12}=3.97, P=\right.$ 0.047), being higher for the high and low sheep density than for the no sheep population (Fig. 6b). For the other life-history components, no variation in summed elasticities was found among sheep density treatments (results not shown).

\section{Life-table response experiments}

Relative to the other treatments, there was a (small) positive effect of low sheep density on $\lambda$, due mainly to a high positive contribution from growth. Effects of high sheep density and no sheep were both small and negative (Fig. 7a; mean of absolute values of sheep density effects $\pm \mathrm{SD}$ : $0.017 \pm 0.005, n=3$ ). High sheep density reduced $\lambda$ most notably by reducing stasis and growth, but high clonal reproduction and retrogression buffered these negative effects. In the no sheep treatment, reduced clonal 


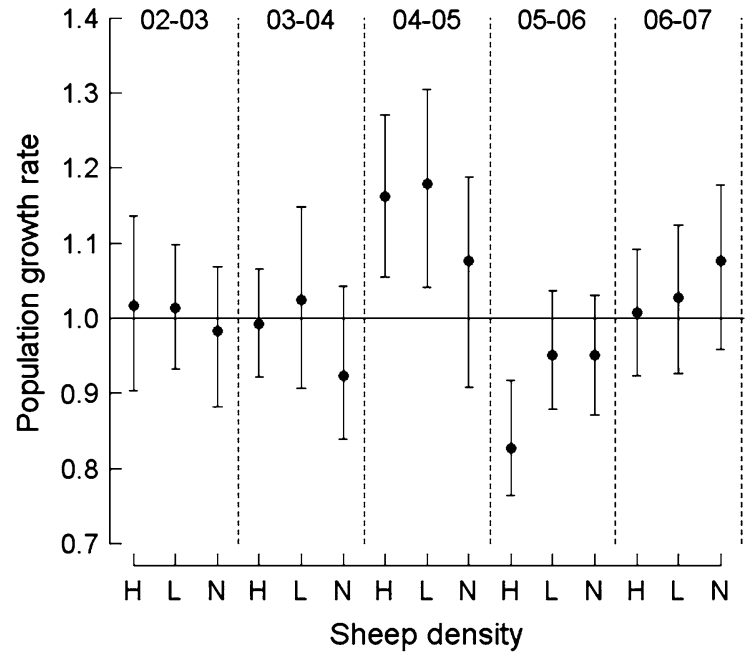

Fig. 5 Population growth rates $(\lambda)$ for Geranium sylvaticum in the three populations exposed to high sheep density $(H)$, low sheep density $(L)$ and no sheep $(N)$, over five transition periods. The error bars are $95 \%$ bootstrapped confidence intervals (3000 bootstrap replicates)

reproduction, growth and retrogression contributed to a negative effect on $\lambda$, whilst stasis provided the largest positive contribution to $\lambda$.

The year effect on variation in $\lambda$ was on average 3.5 times larger than the effect of sheep density (Fig. 7b; mean of absolute values \pm SD: $0.059 \pm 0.050$, $n=5$ ). A positive correlation between net contributions from growth to variation in $\lambda(r=0.900, \mathrm{df}=3$, $P=0.038$ ) was found, as well as a tendency for negative correlation between net contributions from retrogression ( $r=-0.869$, $\mathrm{df}=3, P=0.056$ ). The largest positive effect on $\lambda$ was observed for 2004-2005, whereas the largest negative effect was observed for 2005-2006.

The net interaction effects were intermediate between the year and treatment effects (Fig. 7c; average of absolute values $\pm \mathrm{SD} ; 0.032 \pm 0.019$, $n=15$ ). Interaction effects were positive in a minimum of two transition periods in all populations, confirming that no population consistently had higher $\lambda$ than the others.

\section{Discussion}

Tolerance to grazing, i.e., the ability to regrow and/or reproduce after a grazing event (Strauss and Agrawal 1999), is dependent on both frequency and intensity of grazing (del-Val and Crawley 2005). Grazing intensity on Geranium sylvaticum, expressed in terms of proportion of biomass removed, is low in this study; normally only 1-2 leaves are removed (M. Evju, unpublished data). Our results demonstrate that growth of individual ramets is reduced with grazing, but at the same time, increased rates of clonal reproduction following grazing suggest that this species is indeed tolerant to the grazing intensity observed in this study. The grazing pressure on G. sylvaticum in the study area is relatively low compared to other herbs (Evju et al. 2006), and our results are in line with results of other studies showing that herbs are able to tolerate low levels of grazing (Huhta et al. 2003; Moser and Schutz 2006).

These effects of grazing on individual ramets are visible at the population level as higher rates of retrogression (i.e. survival to a smaller life-stage class) and clonal reproduction in the high sheep density treatment. These effects partly buffer negative effects of reduced rates of growth and stasis (survival to a larger or the same life-stage class, respectively). Nonetheless, even at high sheep densities, the proportion of plants being grazed is low (the maximum in 1 year is $16 \%$ ). Consequently, no consistent differences in population growth rate $(\lambda)$ occur between populations exposed to high, low or zero sheep densities. At the time-scale included in this study, high sheep density does not impact the population in the high sheep density treatment negatively. This accords with the finding of Doak (1992) that frequent, but low-intensity insect attacks on Epilobium latifolium have small effects on population growth.

Repeated defoliation is expected to deplete the plants' resource pools, and thereby to reduce the plants' ability to express tolerance to grazing (del-Val and Crawley 2005). Reduction of individual size, and thereby a shift in stage distribution towards smaller plants under high sheep densities could, therefore, be expected to reduce $\lambda$ (Knight 2004; Ehrlén 1995b), as survival, fecundity and clonal reproduction rates all increase with size. However, the long lifespan of individual plants, as well as life-history traits such as clonal reproduction, tend to enhance population persistence (Eriksson 1996), and long-lived plants generally show more stable population dynamics than short-lived plants (García et al. 2008; Silvertown et al. 1993). Thus, negative effects of sub-optimal 

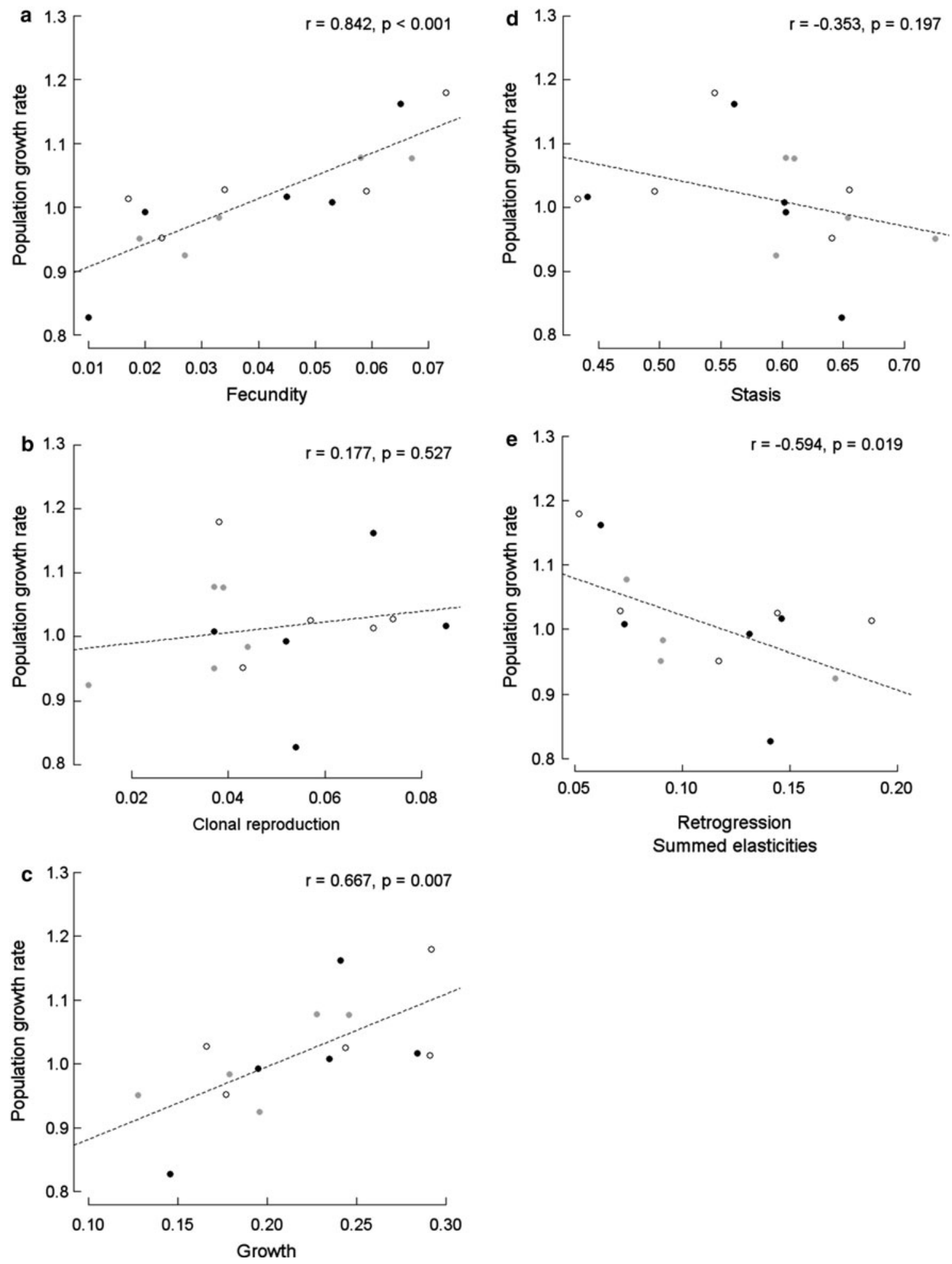

Fig. 6 Correlations between population growth rates and summed elasticities for a fecundity, b clonal reproduction, c growth, $\mathbf{d}$ stasis and e retrogression. Black circles represent

high sheep density; open circles represent low sheep density and grey circles represent no sheep 
Fig. 7 LTRE effects of $\mathbf{a}$ sheep density treatment and $\mathbf{b}$ year on $\lambda$ for Geranium sylvaticum. Contributions of positive and negative matrix elements are separately grouped by life-history components: $F$ fecundity, $C$ clonal reproduction, $G$ growth, $S$ stasis, and $R$ retrogression. c LTRE treatment-by-year interaction effects, only the last digit of the year is shown

environmental conditions could be expected to be delayed (Morris et al. 2008).

Previous studies have found a strong positive effect on biomass of G. sylvaticum after protecting it from grazers in alpine snow beds (Moen and Oksanen 1998), but that the magnitude of the effect depends on habitat productivity (Olofsson 2001). In our study area, G. sylvaticum is most abundant in productive habitats, which are also favoured by sheep (Mobæk et al. 2009), and our results do not support a general positive effect of excluding sheep. On the contrary, we find that at the population level, the relative importance of growth is less and that of stasis is larger, in the no sheep treatment compared to low sheep density. Accumulation of biomass in G. sylvaticum is strongly linked to light conditions (Salomonson et al. 1994). If sheep grazing reduces the abundance of tall neighbours, this could favour G. sylvaticum plants in small life-stage classes in terms of increasing light availability. Consequently, low grazing pressure combined with persistence in ungrazed patches could be hypothesised to buffer the population from impacts of changes in grazing regime (Maron and Kauffman 2006).

Temporal variation in population dynamics

In alpine environments, the climate is unfavourable for sexual reproduction in a high proportion of years (Bell and Bliss 1980), and large interannual variation is typical in seed production (Chambers 1995), seedling recruitment rates (Weppler et al. 2006) and plant growth (Callaghan et al. 1989). In line with this, we find that the $\lambda$ of G. sylvaticum varies among years. Warm summers affect survival, growth, and flowering rates positively; thus, the temporal variation in $\lambda$ can be linked to variations in local summer climate. Particularly low $\lambda$ is found in the 2005-2006 transition, the summer of 2006 being warm and dry, and with early snowmelt (Table 1). Plant growth is positively related to July precipitation, which can explain the low $\lambda$ in the dry year. Furthermore, grazed plants are comparably
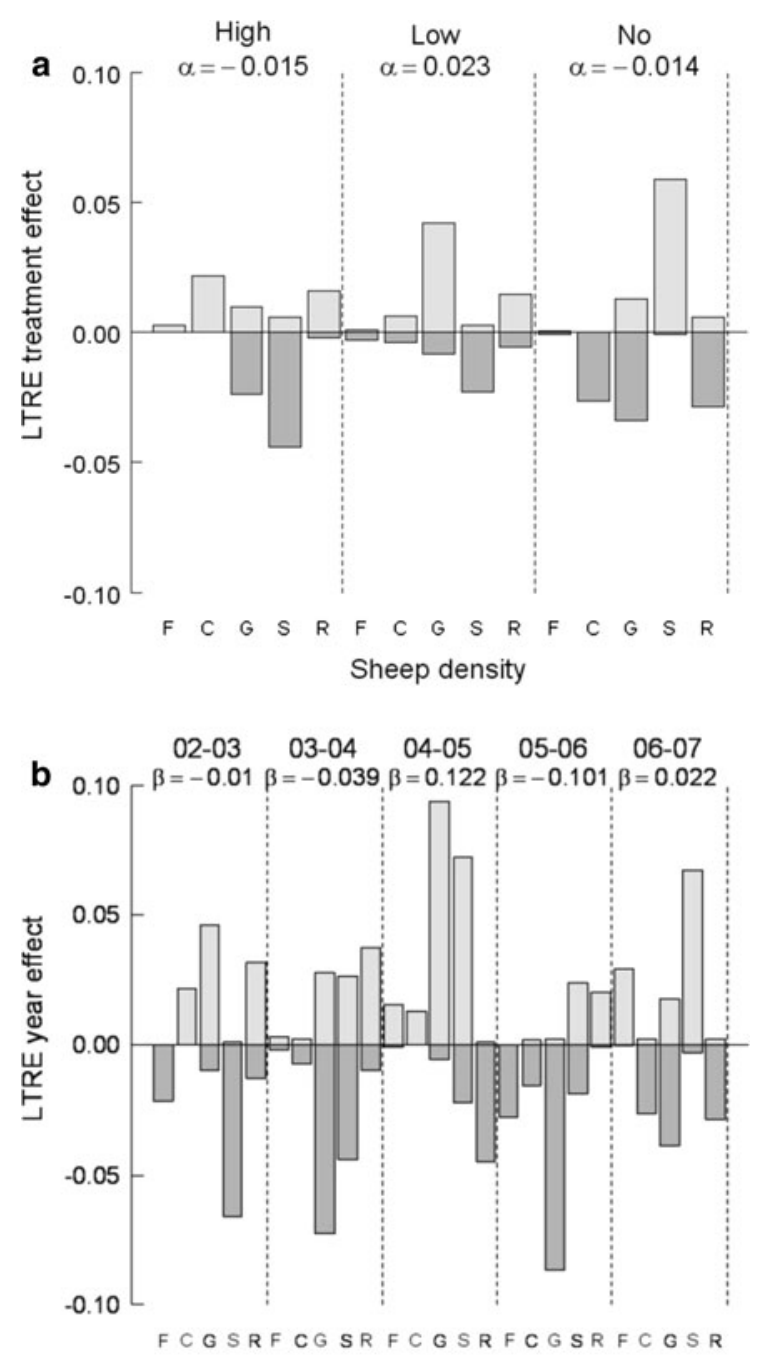

Year

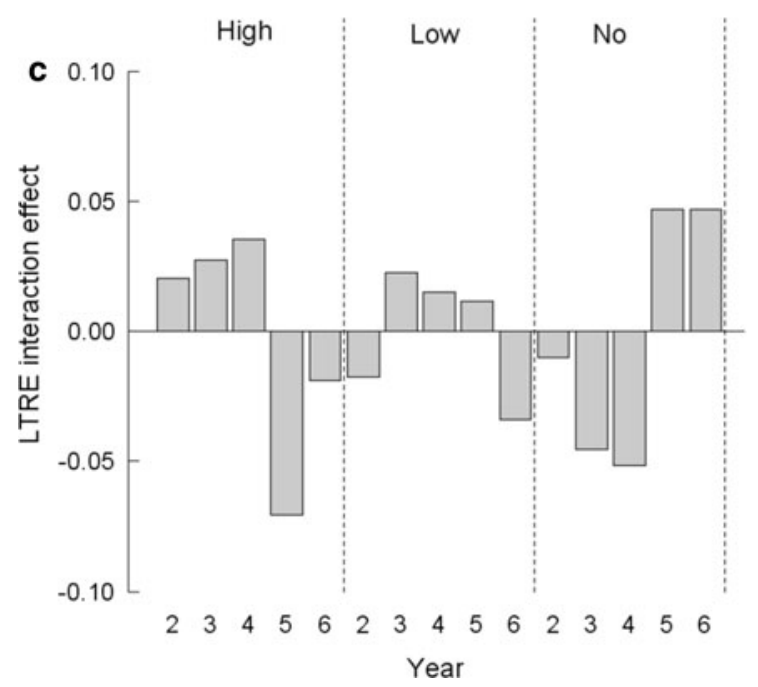


smaller during dry years (significant precipitation $\times$ grazing interaction; Table 3), which supports earlier findings of grazing effects being more severe in unfavourable years (Bastrenta et al. 1995). Ehrlén (1995b) found that $\lambda$ of Lathyrus vernus was lower in a grazed compared to an ungrazed population in one of 3 years only, but few studies of vertebrate grazing have lasted long enough to address temporal variability in demographic rates (Evju et al. 2010; Rydgren et al. 2007).

\section{Conclusion}

In this study, sheep are stocked at densities that are representative of densities in Norwegian mountain pastures. Observable effects of grazing pressure on Geranium sylvaticum are low to moderate and, consequently, sheep grazing treatment is not a major determinant of variation in population growth rate. The increase in relative importance of clonal reproduction with enhanced grazing pressure (from no via low to high sheep density), does, however, suggest that increased clonal reproduction rates function as a tolerance mechanism towards grazing for this herb. However, in this alpine study area, variable climatic conditions seem in general to overrule effects of grazing on population growth rate.

Acknowledgements This study was funded by the Research Council of Norway (Project 153601/432 and 134361/720). We are grateful to Synnøve Lindgren for help with field work in 2003, and to Dagrun Vikhamar Schuler at the Norwegian Meteorological Institute for providing interpolated climate data.

Open Access This article is distributed under the terms of the Creative Commons Attribution Noncommercial License which permits any noncommercial use, distribution, and reproduction in any medium, provided the original author(s) and source are credited.

\section{References}

Ågren J, Willson MF (1994) Cost of seed production in the perennial herbs Geranium maculatum and G. sylvaticum: an experimental field study. Oikos 70:35-42

Augustine DJ, McNaughton SJ (1998) Ungulate effects on the functional species composition of plant communities: herbivore selectivity and plant tolerance. J Wildl Manage 62(4):1165-1183
Austrheim G, Evju M, Mysterud A (2005) Herb abundance and life-history traits in two contrasting alpine habitats in southern Norway. Plant Ecol 179:217-229

Austrheim G, Mysterud A, Pedersen B, Økland RH, Hassel K, Evju M (2008) Large scale experimental effects of three levels of sheep densities on an alpine ecosystem. Oikos 117:837-846

Bastrenta B (1991) Effect of sheep grazing on the demography of Anthyllis vulneraria in Southern France. J Ecol 79: 275-284

Bastrenta B, Lebreton J-D, Thompson JD (1995) Predicting demographic change in response to herbivory - a model of the effects of grazing and annual variation on the population dynamics of Anthyllis vulneraria. $\mathrm{J}$ Ecol 83:603-611

Bates D, Maechler M (2010) Lme4: linear mixed-effect models using s4 classes. R package version 0.999375-33. http:// CRAN.R-project.org/package $=$ lme 4

Bell KL, Bliss LC (1980) Plant reproduction in a High Arctic environment. Arct Alp Res 12:1-10

Brys R, Jacquemyn H, Endels P, De Blust G, Hermy M (2004) The effects of grassland management on plant performance and demography in the perennial herb Primula veris. J Appl Ecol 41:1080-1091

Callaghan TV, Carlsson BÅ, Tyler NJC (1989) Historical records of climate-related growth in Cassiope tetragona from the Arctic. J Ecol 77:823-837

Caswell H (2001) Matrix population models: construction, analysis and interpretation, 2nd edn. Sinauer Associates, Sunderland

Chambers JC (1995) Disturbance, life-history strategies, and seed fates in alpine herbfield communities. Am J Bot 82:421-433

Crawley MJ (2007) The R book. Wiley, Chichester

Cronin G, Lodge DM (2003) Effects of light and nutrient availability on the growth, allocation, carbon/nitrogen balance, phenolic chemistry, and resistance to herbivory of two freshwater macrophytes. Oecologia 137:32-41

de Kroon H, van Groenendael J, Ehrlén J (2000) Elasticities: a review of methods and model limitations. Ecology 81: 607-618

del-Val E, Crawley MJ (2005) Are grazing increaser species better tolerators than decreasers? An experimental assessment of defoliation tolerance in eight British grassland species. J Ecol 93:1005-1016

Diemer M, Schmid B (2001) Effects of biodiversity loss and disturbance on the survival and performance of two Ranunculus species with differing clonal architectures. Ecography 24:59-67

Doak DF (1992) Life-time impacts of herbivory for a perennial plant. Ecology 73:2086-2099

Ehrlén J (1995a) Demography of the perennial herb Lathyrus vernus. I. Herbivory and individual performance. J Ecol 83:287-295

Ehrlén J (1995b) Demography of the perennial herb Lathyrus vernus. II. Herbivory and plant population dynamics. J Ecol 83:297-308

Ehrlén J, Lehtilä K (2002) How perennial are perennial plants? Oikos 98:308-322

Ehrlén J, Syrjänen K, Leimu R, García MB, Lehtilä K (2005) Land use and population growth of Primula veris: an 
experimental demographic approach. J Appl Ecol 42: 317-326

Eriksson O (1996) Regional dynamics of plants: a review of evidence for remnant, source-sink and metapopulations. Oikos 77:248-258

Evju M (2009) Sheep grazing and dynamics of alpine plants in a landscape-scale experiment. Dissertation, University of Oslo

Evju M, Mysterud A, Austrheim G, Økland RH (2006) Selecting herb species and traits as indicators of sheep grazing pressure in a Norwegian alpine habitat. Écoscience 13:459-468

Evju M, Halvorsen R, Rydgren K, Austrheim G, Mysterud A (2010) Interactions between local climate and grazing determine the population dynamics of the small herb Viola biflora. Oecologia 163:921-933

Førland EJ (1993) Precipitation normals, period 1961-1990. Norwegian Meteorological Institute 39:1-63

García MB, Picó FX, Ehrlén J (2008) Life span correlates with population dynamics in perennial herbaceous plants. Am J Bot 95:258-262

Hæggström C-A (1990) The influence of sheep and cattle grazing on wooded meadows in Åland, SW Finland. Acta Bot Fenn 141:1-28

Huhta A-P, Hellstrõm K, Rautio P, Tuomi J (2003) Grazing tolerance of Gentianella amarella and other monocarpic herbs: why is tolerance highest at low damage levels? Plant Ecol 166:49-61

Hunt LP (2001) Heterogeneous grazing causes local extinction of edible perennial shrubs: a matrix analysis. J Appl Ecol 38:238-252

Jefferies RL (1999) Herbivores, nutrients and trophic cascades in terrestrial environments. In: Olff H, Brown VK, Drent RH (eds) Herbivores: between plants and predators. Blackwell Publishing, Oxford, pp 301-330

Kausrud K, Mysterud A, Rekdal Y, Holand $\varnothing$, Austrheim G (2006) Density dependence in foraging behaviour of sheep on alpine pastures: effects of scale. J Zool 270:63-71

Kéry M, Gregg KB, Schaub M (2005) Demographic estimation methods for plants with un-observable life-states. Oikos 108:307-320

Klimeš L, Klimešová J (1999) Clo-pla2—a database of clonal plants in Central Europe. Plant Ecol 14:9-19

Knight TM (2003) The effects of herbivory and pollen limitation on the population dynamics of Trillium grandiflorum. Dissertation, University of Pittsburgh

Knight TM (2004) The effect of herbivory and pollen limitation on a declining population of Trillium grandiflorum. Ecol Appl 14:915-928

Korhonen J, Kytöviita M-M, Siikamäki P (2004) Are resources allocated differently to symbiosis and reproduction in Geranium sylvaticum under different light conditions? Can J Bot 82:89-95

Lamoureaux SL, Kelly D, Barlow ND (2003) Population dynamics in mature stands of Hieracium pilosella in New Zealand. Plant Ecol 166:263-273

Lenart EA, Bowyer T, Ver Hoef J, Ruess RW (2002) Climate change and caribou: effects of summer weather on forage. Can J Zool 80:664-678

Lennartsson T, Oostermeijer JGB (2001) Demographic variation and population viability in Gentianella campestris: effects of grassland management and environmental stochasticity. J Ecol 89:451-463

Lennartsson T, Nilsson P, Tuomi J (1998) Induction of overcompensation in the field gentian, Gentianella campestris. Ecology 79:1061-1072

Lesica P, Steele BM (1994) Prolonged dormancy in vascular plants and implications for monitoring studies. Nat Areas J 14:209-212

Lid J, Lid DT (2005) Norsk flora, 7th edn. Det Norske Samlaget, Oslo

Maron JL, Crone E (2006) Herbivory: effects on plant abundance, distribution and population growth. Proc R Soc B 273:2575-2584

Maron JL, Kauffman MJ (2006) Habitat-specific impacts of multiple consumers on plant population dynamics. Ecology $87: 113-124$

Martorell C (2007) Detecting and managing an overgrazingdrought synergism in the threatened Echeveria longissima (Crassulaceae): the role of retrospective demographic analysis. Popul Ecol 49:115-125

Maschinski J, Whitham TG (1989) The continuum of plant responses to herbivory: the influence of plant association, nutrient availability and timing. Am Nat 134:1-19

Mobæk R, Mysterud A, Loe LE, Holand $\varnothing$, Austrheim G (2009) Density dependent and temporal variability in habitat selection by a large herbivore: an experimental approach. Oikos 318:209-218

Moen J, Oksanen L (1998) Long-term exclusion of folivorous mammals in two arctic-alpine plant communities: a test of the hypothesis of exploitation ecosystems. Oikos 82: 333-346

Molau U, Larsson EL (2000) Seed rain and seed bank along an alpine altitudinal gradient in Swedish Lapland. Can J Bot 78:728-747

Morris WF, Pfister CA, Tuljapurkar S et al (2008) Longevity can buffer plant and animal populations against changing climatic variability. Ecology 89:19-25

Moser B, Schutz M (2006) Tolerance of understory plants subject to herbivory by roe deer. Oikos 114:311-321

Mulder CPH (1999) Vertebrate herbivores and plants in the arctic and subarctic: effects on individuals, populations, communities and ecosystems. Perspect Plant Ecol Evol Syst 2:29-55

Olofsson J (2001) Influence of herbivory and abiotic factors on the distribution of tall forbs along a productivity gradient: a transplantation experiment. Oikos 94:351-357

Pinheiro J, Bates D (2000) Mixed-effect models in S and S-PLUS. Springer, New York

Pinheiro J, Bates D, DebRoy S, Sarkar D, R Development Core Team (2008) Nlme: linear and nonlinear mixed effect models. $\mathrm{R}$ package version 3:1-88

R Development Core Team (2009) R: a language and environment for statistical computing. R Foundation for Statistical Computing, Vienna

Rydgren K, de Kroon H, Økland RH, van Groenendael J (2001) Effects of fine-scale disturbances on the demography and population dynamics of the clonal moss Hylocomium splendens. J Ecol 89:395-405

Rydgren K, Økland RH, Picó FX, de Kroon H (2007) Moss species benefits from breakdown of cyclic rodent dynamics in boreal forests. Ecology 88:2320-2329 
Salomonson A, Ohlson M, Ericson L (1994) Meristem activity and biomass production as response mechanisms in two forest herbs. Oecologia 100:29-37

Sigmond E (1998) Odda map of rock; Odda; 1:250 000. Norwegian Geological Surveys, Trondheim

Silvertown J, Franco M, Pisanty I, Mendoza A (1993) Comparative plant demography-relative importance of lifecycle components to the finite rate of increase in woody and herbaceous perennials. J Ecol 81:465-476

Strauss SY, Agrawal AA (1999) The ecology and evolution of plant tolerance to herbivory. Trends Ecol Evol 14: 179-185

Stubben C, Milligan B, Nantel P (2008) Popbio: construction and analysis of matrix population models. $\mathrm{R}$ package version 1.1 .8
Thompson K, Bakker JP, Bekker RM (1997) The soil seed banks of North West Europe: methodology, density and longevity. Cambridge University Press, Cambridge

Tolvanen A, Schroderus J, Henry GHR (2001) Demography of three dominant sedges under contrasting grazing regimes in the High Arctic. J Veg Sci 12:659-670

Weppler T, Stoll P, Stöcklin J (2006) The relative importance of sexual and clonal reproduction for population growth in the long-lived alpine plant Geum reptans. J Ecol 94: 869-879 